\title{
AN INVESTIGATION ON THE ROLE OF REFERENTIALITY IN THE INTERPRETATION OF RELATIVE CLAUSES IN BRAZILIAN PORTUGUESE
}

Gitanna Bezerra ${ }^{1^{*}}$

${ }^{1}$ Universidade Federal de Santa Catarina, Florianópolis, SC, Brasil

\begin{abstract}
This paper presents an off-line experiment we conducted to investigate the influence of referentiality on relative clause (RC) interpretation in Brazilian Portuguese. RCs associated with complex NPs seem to be preferentially attached to a referential noun. This referentiality effect can be treated in discourse terms (Gilboy, Sopena, Clifton \& Frazier, 1995) or in syntacticsemantic terms (Bezerra, 2017; this paper). Our questionnaire tested these approaches using two types of complex NPs (occupational and kinship NPs) and the results showed that the syntactic-semantic structure of these complex NPs can account for the referentiality effect reported in the literature by Gilboy et al. (1995). Based on our results, we argue in favor of the syntactic-semantic approach and show that the discourse-oriented approach lacks explanatory power.

Keywords: Relative Clause Processing; Referentiality; Complex Noun Phrases; Brazilian Portuguese.
\end{abstract}

\footnotetext{
"Has a Ph.D. in Linguistics (Federal University of Paraiba, Brazil) and a Post-Doctorate in Linguistics (University of Toronto, Canada). Currently, she is a Postdoctoral Researcher at the Federal University of Santa Catarina, where she is developing a research project on relative clause processing. She develops research on sentence processing from a grammatical perspective, focusing on phenomena at the syntax-semantics interface. E-mail: gitannabezerra@gmail.com. ORCID: https://orcid.org/0000-0001-5433-387X.
} 


\section{Introduction}

The ultimate question of the Sentence Processing area is how human beings are able to attribute an interpretation to a sentence. What allows us to understand a sentence like "John bought a house"? What happens in our minds when we process such a sentence and get its meaning? We consider, along with a solid body of experimental and theorical research on sentence processing (Frazier \& Fodor, 1978; Frazier, 1979; Frazier \& Rayner, 1982; Frazier, 1987; Frazier, 1990; Frazier \& Clifton, 1996, 1997), that the process of interpretation is preceded by the development of a syntactic representation - the parser, a syntactic processor, is responsible for attributing a syntactic representation to the linguistic input, based on which an interpretation can be achieved. The process of developing a syntactic structure to the linguistic input has been the target of extensive psycholinguistic debate (Frazier, 1979; Frazier \& Rayner, 1982; Frazier \& Clifton, 1996; Altmann \& Steedman, 1988; Karimi \& Ferreira, 2016), but the appropriateness of specific principles, such as the Minimal Attachment Principle, postulated within the framework of the Garden-Path Theory (Frazier \& Fodor, 1978; Frazier, 1979; Frazier \& Rayner, 1982), has been widely attested across languages, allowing us to predict that, in case of structural ambiguities, for example, the parser follows the analysis that corresponds to the simplest syntactic representation. The nature of the process of interpretation, however, is much less clear, and we can enumerate at least two reasons for that: first, it is subject to vagueness with respect to the level of commitment that is necessary to interpret a word or a phrase (e.g., while two senses of a polysemic word may be appropriate in a situation, allowing for a semantic decision to remain open, a totally different picture could be found in another situation), making it hard to specify systematic procedures of the semantic processor and to make context-independent predictions; second, it is a process in which a huge amount and diversity of information can come into play (involving, for instance, semantics, pragmatics, discourse context, and world knowledge), making it difficult to develop a specific hypothesis about the architecture of the cognitive mechanism responsible for carrying out such a task (Frazier, 1999). In this paper we attempt to contribute to this psycholinguistic debate about sentence interpretation by presenting a research we conducted to investigate the influence of referentiality on the interpretation of relative clauses in BP. We looked at ambiguous sentences like the following:

(1)

a. O diretor demitiu o assistente( $(\mathrm{N} 1)$ de gerente(N2) que traiu a empresa na contabilidade.

the director dismissed the assistant of manager that betrayed the company in the accounting

b. Oenfermeiro acalmou o neto $(\mathrm{N} 1)$ de ator $(\mathrm{N} 2)$ que sofreu um acidente na rodovia. the nurse calmed the grandson of actor that had an accident on the highway 
The sentences (1a) and (1b) are ambiguous between a reading in which the relative clause modifies the $\mathrm{N} 1$ and a reading in which the relative clause modifies the N2. In (1a), the two possible interpretations are that "the assistant betrayed the company" if the relative clause is attached to N1, and that "the manager betrayed the company" if the relative clause is attached to N2; whereas in (1b) the possibilities are that "the grandson had an accident", in case of N1 attachment, and that "the actor had an accident", in case of N2 attachment. The key difference between (1a) and (1b) lies in the nature of the complex NP (N1of-N2) the relative clause is associated with: in (1a), the complex NP expresses an occupational relation, and in (1b) the complex NP expresses a kinship relation. The processing of this type of structural ambiguity involving relative clauses has been the focus of intense debate in the Sentence Processing area, and what the studies conducted over the years have been showing is that there is no systematic preference, either favoring attachment to N1 or to N2, across languages (Cuetos \& Mitchell, 1988; Gibson, Pearlmutter, Canseco-Gonzalez \& Hickok, 1996; Fodor, 1998, 2002; Hemforth, Konieczny, Seelig \& Walter, 2000; Maia, Fernández, Costa \& Lourenço- Gomes, 2006; Grillo \& Costa, 2014; Hemforth, Fernandez, Clifton, Frazier, Konieczny \& Walter, 2015). In this paper we want to investigate whether there will be a preference for N1 or N2 attachment in sentences like (1a) and (1b) in BP. More specifically, our aim is to investigate whether one linguistic factor may influence the relative clause interpretation, namely, the referential status of $\mathrm{N} 1$ and N2, and we will look at it based on two types of complex NPs (kinship relation and occupational relation).

The relevance of referentiality to the interpretation of relative clauses associated with complex NPs was already pointed out in the literature by Gilboy, Sopena, Clifton, and Frazier (1995). Based mainly on English data, these authors postulated the Referentiality Principle, which predicts that restrictive modifiers, like the relative clauses in (1a) and (1b), preferentially look for hosts that are referential, that is, that correspond to discourse entities in a certain discourse model, assuming that a noun is referential in this sense when introduced by a determiner. On the assumption that this prediction is accurate, we could easily foresee a preference for N1 attachment both in (1a) and (1b), since only the N1 is referential in these cases. Besides that, we could also predict that, in case we make the N2 referential by adding a determiner (producing complex NPs like " $o$ assistente do gerente" ("the assistant of the manager") and "o neto do ator" ("the grandson of the actor"), for example), the preference for N1 modification would be attenuated since the $\mathrm{N} 2$ now would be more accessible to the relative clause in terms of referentiality. These predictions, which appeal to the discourse models built for the sentences, seem to be very straightforward, and the question arises whether our research can offer new insights on the phenomenon. It happens though that we believe such predictions are not that obvious, and we want to explore in this paper the idea that the Referentiality Principle actually does not make accurate predictions about the interpretation of sentences like (1b), which differ from sentences like (1a) with respect to the type of complex NP the 
relative clause is associated with. Intuitively, in (1b) there seems to be a higher preference for N2 modification (at least in comparison with (1a)), and that is so even in the presence of an N2 that might be, at first, regarded as non-referential according to Gilboy et al. (1995), since it is not introduced by a determiner. This intuition calls for a better understanding of the notion of referentiality and how it may affect relative clause interpretation. Bezerra (2017) noticed this need and provided a syntactic-semantic hypothesis for the type of referentiality effect that was found by Gilboy et al. (1995). Based on BP data, the author emphasized that, before looking at the discourse representation that is ultimately built for the sentences and linking the referentiality status of a noun to the mere presence of an overt determiner, it was necessary to look at the syntactic-semantic structure underlying the relationship between the $\mathrm{N} 1$ and the $\mathrm{N} 2$ and the referential status of such nouns. In the same vein, we believe it is crucial to look both at the syntactic-semantic structure that underlies the referentiality of a noun and at its implications for the interpretation of the sentences in hand.

With that being said, the questions that motivated this research were the following: (i) will there be an influence of referentiality on relative clause interpretation in the terms of Gilboy et al. (1995) (roughly speaking, a noun is referential when corresponds to an entity in the discourse model, and this is so when it is introduced by a determiner)?; (ii) Will the influence of referentiality on relative clause interpretation be modulated by the type of complex NP (which comes down to the nature of the syntactic-semantic structure underlying the relationship between the N1 and the N2 (Bezerra, 2017), as will become clearer later in this paper)? To answer these questions, we conducted a questionnaire study with native speakers of BP. We have chosen this off-line technique because we did not want to look at how referentiality and the type of complex NP would impact the real-time processing, but at how such factors would affect the interpretation of our sentences in a broader sense. Our general hypotheses are that there will be an influence of referentiality on relative clause interpretation and that it will be modulated by the type of complex NP (answering "yes" to question (ii) and "no" to question (i)).

To present in more detail the theoretical discussion about our phenomenon and to discuss the experimental evidence we obtained, we are going to take the following path in this paper: in section 2, we develop the theoretical debate surrounding the processing of relative clauses, focusing on the Referentiality Principle and on the framework within which such principle was developed, namely, the Construal Hypothesis (Frazier \& Clifton, 1996, 1997), and discussing Bezerra's (2017) syntactic-semantic hypothesis; in section 3, we present the methodological aspects of our research, describing the experiment we conducted and presenting and discussing the results we obtained; in section 4 , we make a general discussion considering the existing theoretical debate about our phenomenon and how the experimental evidence we obtained may shed some light on the understanding of the influence of referentiality on relative clause interpretation. 


\section{Relative Clause Processing, Construal Hypothesis, and Referentiality Principle}

The processing of ambiguous structures such as (1a) and (1b), in which restrictive relative clauses are associated with complex NPs and can be either attached to $\mathrm{N} 1$ or N2, has been the focus of intense theoretical and experimental debate in the Sentence Processing area for over thirty years now. To understand why this kind of ambiguous structure revealed itself to be so scientifically productive, we need to look at the very first work that was carried out about it: Cuetos and Mitchell (1988). These authors conducted experiments to investigate how native speakers of Spanish would process sentences like (2a) and how native speakers of English would process sentences like (2b):

(2)

a. Alguien disparó contra el criado de la actriz que estaba en el balcón.

b. Someone shot the servant of the actress that was on the balcony.

The data revealed a preference for N1 modification in Spanish and a preference for N2 modification in English. This pattern of results was particularly informative and puzzling because it called into question one of the principles of the Garden-Path Theory, which was being successfully developed by Frazier and colleagues at the time and remains, today, one of the most important theories in the Sentence Processing area. The principle in question is called "Late Closure".

The Garden-Path Theory (Frazier 1979; Frazier \& Rayner 1982; Frazier, 1987; Frazier 1990) is widely referred to in the sentence processing literature as a "syntax-first" model, and that is so because one of its fundamental ideas is that to interpret a given sentence not only does the parser, whose job is to develop syntactic skeletons to the linguistic input, need to attribute it a syntactic representation, but it does so in a very restricted manner, that is, only accessing syntactic information - the parser is informationally encapsulated. In essence, according to this theory, the use of semantic information and the development of a semantic representation, which takes us to the interpretation of the sentence, are always preceded by the use of syntactic information and the development of a syntactic representation. These assumptions are applied to explain the parser's behavior in case of syntactic ambiguities: it always makes immediate and determined decisions based solely on syntactic information, pursuing at all times just one analysis, namely, the one that makes itself first available to it. Two main principles, which are, as we should expect, structural in nature, compose this theory - the Minimal Attachment Principle and the Late Closure Principle. The first one predicts that when two analyses are available and one of them is structurally more complex than the other the parser will see first and pursue the one the is less complex. The second one, which is of particular interest for us in this paper, predicts that when the two analyses available are equally complex in 
structural terms the parser will follow the one that best fits what it is working on at the moment, that is, the analysis that implies an attachment to the phrase or clause currently being processed.

Having put the Late Closure Principle into context, we can now think of what it would predict for the processing of relative clauses associated with complex NPs and address the question of why Cuetos and Mitchell's (1988) results were problematic to it. A sentence like (2a), and its English counterpart (2b), is ambiguous between "el criado estaba en el balcón" (N1 modification) and "la actriz estaba en el balcón" (N2 modification), and both of these analyses are supposed to involve the same structural complexity, since they would equally require the postulation of an additional node, namely, an NP. The Minimal Attachment Principle, therefore, had nothing to say about this. The Late Closure Principle, however, was expected to make very clear predictions about it: the parser would attach the relative clause to the phrase currently being processed, which happens to be the N2.

Besides that, considering that the Late Closure Principle was postulated as a natural result of the very architecture of the human sentence processing mechanism (the parser), the prediction for a preference for N2 modification was expected to be universal, that is, to be equally observed across languages. Now we can see why Cuetos and Mitchell's (1988) results were so puzzling and tricky - they called into question not only the universality of the Late Closure Principle but also the universality of the parser itself. If the Late Closure Principle were universal and accurate, both native speakers of Spanish and native speakers of English should have preferred N2 modification, which did not happen, as we mentioned earlier. As we can imagine, these divergent results led, on the one hand, to a discussion about the explanatory power of the Garden-Path Theory and, on the other hand, to the development of a number of experiments in several languages in an attempt to understand the parser's behavior in the face of this kind of structural ambiguity. As it turns out, this pattern of results was not an isolated incident: the results that have been obtained across languages over the years do not show either a systematic preference N2 modification (or even N1 modification) in the processing of this type of structure. We can actually find divergent results within the same language. This is the case of BP. We can mention at least three lines of results to illustrate this. Ribeiro $(1998,2004,2005)$, for instance, reported off-line and on-line preferences for N1 attachment. Miyamoto (1999), on his turn, reported an on-line preference for N2 attachment (Miyamoto (2005), however, reanalyzed this finding, acknowledging that it could be actually linked to an interference effect related to the type of disambiguating material that was used, namely, number agreement). Finally, Maia, Fernández, Costa and LourençoGomes (2006) argued in favor of a clear pattern in the preferences of analysis in BP: on-line preference for N2 attachment, and off-line preference for N1 attachment. This paper by Maia et al. (2006) is a very strong reference on the topic, but the fact is that the discussion remains open, especially if we consider 
that different factors can come into play in the processing of relative clauses, as will become clear throughout this section of the paper.

As a way of showing the productivity of this debate on relative clause processing, I can mention some hypotheses that were developed in an effort to understand and explain the processes involved in the resolution of this type of ambiguity: Tuning Hypothesis (Mitchell \& Cuetos, 1991), Construal Hypothesis (Frazier \& Clifton, 1996, 1997), Recency Preference \& Predicate Proximity (Gibson, Pearlmutter, Canseco-Gonzalez \& Hickok, 1996), Implicit Prosody Hypothesis (Fodor, 1998, 2002), Attachment-binding dualism (Hemforth, Konieczny, Seelig \& Walter, 2000), and PR-first Hypothesis (Grillo \& Costa, 2014). In this paper we are going to talk more about the Construal Hypothesis, since the discussion we are making about the influence of referentiality on relative clause interpretation was brought out by a non-structural principle postulated within its framework - the Referentiality Principle (Gilboy et al., 1995).

The Construal Hypothesis was postulated by Frazier and Clifton (1996) as a reformulation of the Garden-Path Theory largely in response to the studies on relative clause processing that put into question the accurateness of the Late Closure Principle. Frazier and Clifton (1996) acknowledged the fact that Late Closure could not account for the processing of relative clauses associated with complex NP but they also proposed that such principle should not be expected to account for it anyway because it just does not operate in the processing of that type of structure. The idea is that the parser proceeds differently, either following or not structural principles such as Late Closure and Minimal Attachment, depending on the type of structure or relation it finds in the input. In this regard, the authors make a fundamental distinction between primary phrases and relations and secondary phrases and relations. The first type refers to the subject and main predicate of any (+ or -) finite clause, and to obligatory constituents of primary phrases. The second type refers to those phrases or relations that are grammatically optional, that is, that are not imperative for the global grammatical well-formedness of the sentence. Roughly speaking, we are dealing with the difference between arguments and adjuncts, between the phrases or relations that are part of the requirements of a linguistic element (e.g., a verb or a noun) and are crucial to identifying its appropriate lexical description in a given sentence, and the relations that have no role in determining the analysis of a lexical item. Construal's proposal is that primary phrases and secondary phrases are subject to different processing mechanisms. When parsing primary phrases, the parser always develop immediate fully determinate analysis, making premature decisions that may turn out to be wrong later and require reanalysis. This way of proceeding is called "attachment". On the other hand, when parsing secondary phrases, the parser may allow for an underspecification in the syntactic phrase marker, that is, it may not fully determine immediate domination and sisterhood relations. In this case, the parser proceeds initially in a way that is called "association": it associates the secondary phrase into the current thematic processing domain (the extended projection of the last thetaassigner). This process is illustrated in Picture 1: 
Picture 1: Analysis of a secondary phrase via association

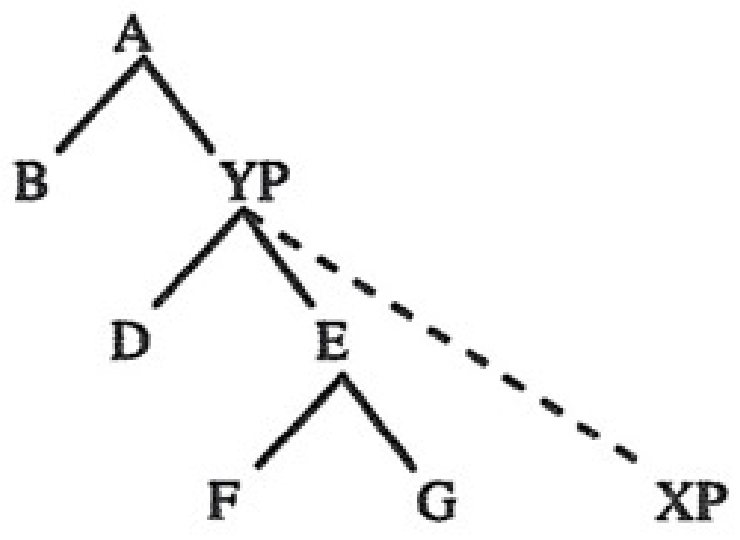

Source: Frazier and Clifton (1997, p. 280).

The question now is how we get to interpret a sentence with an ambiguity involving a secondary phrase or relation if the structure itself does not determine one analysis. Frazier and Clifton $(1996,1997)$ propose that after association a process of interpretation takes place, and it is carried out using structural and nonstructural information and principles. Considering Picture 1, the idea is that one specific syntactic analysis will be ultimately attributed to the secondary phrase $\mathrm{XP}$ within the domain established by YP (XP will find a sister node within YP, which may be YP itself) and such analysis will be developed in a way that is not informationally encapsulated, that is, it may be reached by using information that comes from syntax, semantics, pragmatics, prosody, and/or discourse, for example. The possible use of such a range of information would be on the basis of the variability in the preferences of analysis of secondary phrases (such as the relative clauses we are focusing on) across languages or even within a language - the divergent results about relative clause processing, therefore, were accounted for and the universality of Late Closure was preserved. The authors did not lay out exactly, however, the nature of the processor that is going to carry out this interpretation, leaving open the questions of how it is structured and how it operates (what motivates or restricts its decisions? How does it communicate with the syntactic processor (the parser), for example?). As the authors themselves emphasized, these questions can only be properly addressed once we have a better understanding of semantic processing. Our paper is an attempt to contribute to this debate and we do so by focusing on a non-structural principle, namely, the Referentiality Principle, to understand how referentiality affects relative clause interpretation.

The Referentiality Principle was proposed by Gilboy et al. (1995) within the scope of the Construal Hypothesis. Construal says that relative clauses such as the ones we are studying are processed in the following way: first, the parser associates the relative clause into the current thematic processing domain, and then a process of interpretation occurs in which the relative clause is attached to a specific node based on the relevant information that is available, be it structural or non-structural. The Referentiality Principle is predicted to be part 
of this process of interpretation, and it emphasizes the role of referentiality in determining the analysis of the relative clause. More specifically, it says that a restrictive relative clause will preferentially look for hosts that are referential in the sense that introduce entities into a discourse model or correspond to entities already present in a discourse model. Gilboy et al. (1995) assume that a noun is referential in this sense when it is introduced by a determiner (more precisely, an overt determiner). They tested this prediction looking at the interpretation of relative clauses associated with complex NPs of "substance reading" (such as "the shoe of cotton") and of "quantity reading" (such as "the glass of water"), which contain, more naturally, a referential N1 and a non-referential N2 - a biased situation, we must say. In questionnaires studies conducted with native speakers of English and native speakers of Spanish, they investigated the interpretation of sentences like the following (among others):

(3)

a. Yesterday they gave me the sweater of cotton that was illegally imported.

b. Ayer me regalaron el jersey de algodón que importaban de contrabando.

In these sentences, we find substance NPs with a referential N1 and a nonreferential N2, and Gilboy et al.'s (1995) expectations were that there would be a preference for $\mathrm{N} 1$ modification in both languages ${ }^{1}$. Indeed, the results showed this to be the case. Considering, more specifically, the English data, only $26 \%$ of N2 responses were obtained in sentences like (3a) - the referential N1 was preferred as the host of the relative clause over the non-referential N2. This result was also fully consistent with the Construal Hypothesis: a non-structural information would be motivating a preference for N1 modification even in English, which was, and still is, regarded as a "N2-attachment language" in the literature on relative clause processing.

Gilboy et al. (1995) conducted another questionnaire, this time only with native speakers of English, to test the Referentiality Principle in another situation. On the assumption that a noun is referential when introduced by a determiner, the authors went further and just added an overt determiner to the N2 in sentences like (3a), expecting that this would cause an increase in the preference for N2 modification if their predictions were on the right track. They looked at the interpretation of sentences like (4):

(4) Yesterday they gave me the sweater of the cotton that was illegally imported.

The authors' expectations were borne out by the results: sentences like (4) received $55 \%$ of $\mathrm{N} 2$ responses, a significant increase in the number of N2 responses in comparison with what was observed in sentences like (3a). We think this finding was important because of the bias we mentioned earlier - it showed that it was possible to make the N2 more available for the relative clause 
by adding an overt determiner to it even in a complex NP in which a referential N2 would sound odd.

In sum, the Referentiality Principle is a Construal's interpretive principle which predicts that, when a relative clause is associated into the current thematic processing domain which contains a referential host and a non-referential host, it will be ultimately attached to the host that is referential, that is to say, to the noun that is introduced by a determiner. In case the two hosts that are available in the current thematic processing domain are both referential, however, the Referentiality Principle does not seem to be able to make specific predictions another information or principle, therefore, would have to come into action to attribute a specific host to the relative clause.

The Referentiality Principle was first investigated in BP by Maia and Finger (2007). To test the principle's predictions, the authors looked at the interpretation of sentences like (5), which contain a referential N1 and a non-referential N2:

(5) O rapaz vendeu a mesa de madeira que empena.

the boy sold the table of wood that warps

The results were exactly the ones the authors expected based on Gilboy et al. (1995): there was a general preference for attaching the relative clause to the referential noun - the N1 (69.95\% of N1 responses). Maia and Finger (2007) did not manipulate the N2 referentiality, though. Bezerra (2017) conducted a more extensive investigation on the Referentiality Principle in BP (some of the experimental studies carried out by Bezerra (2017) were published in Bezerra and Leitão (2017), Bezerra, Leitão, and Medeiros (2017), and Bezerra (2019)), and her findings led her to think more critically about the way it was formulated by Gilboy et al. (1995). The author focused on the processing of relative clauses associated with complex NPs of substance reading considering structures like (6a) and (6b):

(6)

a. O policial apreendeu o sapato de couro que foi irregularmente importado pela empresa.

the policeman confiscated the shoe of leather that was illegally imported by the company

b. O policial apreendeu o sapato do couro que foi irregularmente importado pela empresa.

the policeman confiscated the shoe of-the leather that was illegally imported by the company

She conducted several experiments (more specifically, two questionnaires, two self-paced reading tasks, one eye-tracking study, and one acceptability judgment task) and the general results revealed, on the one hand, a pronounced 
preference for N1 modification in sentences like (6a), and, on the other hand, a notable resistance (in the sense of not easily accepting something) to N2 modification, or to a referential N2, actually, in sentences like (6b). For us to have a more clear picture of this pattern, one of the questionnaires the author carried out used precisely sentences like (6a) and (6b) and it captured a preference for N1 modification in both types of sentences $-86.75 \%$ in sentences like (6a) and $62.50 \%$ in sentences like (6b) -, which did not prevent, however, an effect of referentiality from appearing: the probability of choosing the N2 as the host of the relative clause was higher in sentences like (6b) than in sentences like (6a) - $37.5 \%$ vs. $13.75 \%$, respectively. Bezerra (2017) hypothesized that a difference in the syntactic-semantic status of the $\mathrm{N} 1$ and the $\mathrm{N} 2$ would be underlying both the resistance to a referential N2 in complex NPs of substance reading and the preference for $\mathrm{N} 1$ modification that were generally found across her experiments. Her idea was the following: in complex NPs of substance reading like "o sapato de couro" (the shoe of leather), the N1 corresponds to a determiner phrase (DP) and to the semantic type e, whereas the N2 corresponds to an NP and to the semantic type $<\mathrm{e}, \mathrm{t}\rangle$, and the preposition " $d e$ " is athematic and works as a linker, enabling the establishment of a modification relation between the two nouns ${ }^{2}$.

Such a hypothesis, according to the author, would offer a direct explanation for the resistance to a referential N2 in this type of complex NP: if we see the modification relation as a process of "theta identification", as Higginbotham (1985) did, for it to be established both the modifier noun and the modified noun need to have open positions, that is, they have to be NPs $(<e, t>)$, because DPs would have their open positions already filled or satisfied by the determiner; as a consequence, the resistance found in "o sapato do couro" (the shoe of-the leather) would result from the fact that the N2 ("o couro" (leather)), corresponding to a DP, would not have an open position available to establish a modification relation with the N1, possibly engaging in a different type of relation (along the lines of what we see in small clauses, e.g.), considering that "o sapato do couro" (the shoe of-the leather) seems to be focusing more on a process ("the shoe that was made of the leather that...") than on a product ("the leather shoe"). Bezerra (2017) argues that her hypothesis about the syntactic-semantic structure of NPs like " $o$ sapato de couro" (the shoe of leather) would also account for the preference for N1 modification in sentences like (6a): if it is correct that the N1 corresponds to a DP and the N2 corresponds to an NP, they do not exhibit the same syntacticsemantic structure and, therefore, are not equally available ${ }^{3}$ for the relative clause when the parser leaves the complex NP and proceeds to parse the rest of the sentence; according to the author, this state of affairs would predict a difference in terms of processing cost between N1 modification and N2 modification in the following way: assuming that attaching the relative clause to the $\mathrm{N} 2$ would motivate a more specific reading (or even an existential reading) of such a noun and that this reading is often associated with the presence of a null determiner in the case of bare nouns (Coene \& D'hulst, 2003), N1 modification would be preferred because it is simpler in syntactic-semantic terms, that is to say, while 
attaching the relative clause to the N1 would not require any changes in the structure and interpretation already established for the N1 (and the complex NP as whole), attaching it to the $\mathrm{N} 2$ would require at least two additional procedures - (I) the revision of the syntactic-semantic structure that had already been attributed to the N2 (and to the complex NP) and (II) the addition of a new syntactic node (a DP) to the N2 -, which would make the N2 modification the option that involves a higher processing cost, being, therefore, the less preferred analysis. This way of explaining the preference for N1 modification when the substance NP the relative clause is associated with contains a referential N1 and a non-referential N2 challenges the Referentiality Principle in the way it was postulated by Gilboy et al. (1995) because these authors just disregarded the syntactic-semantic structure that underlies the discourse or referential status of a noun, apparently assuming that in terms of syntax and semantics the N1 and the $\mathrm{N} 2$ were alike and that a possible difference in terms of their referential status and in terms of the preferences of analysis of the relative clause could be attributed to another level of representation - discourse representation or mental model structure, without presenting, however, a clear picture of which processor would develop such a structure and how it would communicate with the parser in the process of interpreting the relative clause and determining an attachment site, along the lines of the Construal Hypothesis (Frazier \& Clifton, 1996, 1997). Bezerra (2017) proposes, in sum, that the Referentiality Principle should receive a more syntactic-semantic treatment, and not a general, discourse-based one.

We think Bezerra's (2017) hypothesis is on the right track and needs to be further investigated. This paper is also a movement towards that. We actually want to pose an additional challenge to the Referentiality Principle: do the preferences of analysis it predicts really stem from the fact that relative clauses prefer hosts that are referential in the sense they are introduced by an overt determiner? Gilboy et al. (1995) seem to make this assumption. In the same vein, Frazier and Clifton (1997), in a paper that gives an overview of the Construal Hypothesis, explicitly state that "Modifiers (including relative clauses) preferentially modify phrases which are "referential" in the sense that they are introduced by a determiner." (p. 282). If Bezerra's (2017) approach is accurate, this assumption does not capture and does not explain the preferences of analysis in sentences like (6a): the noun introduced by a determiner is preferred by the relative clause because this analysis is less complex in processing terms than the other one (N2 modification). But, besides that, and most importantly, we want to discuss a case that would go against what Gilboy et al. (1995) predict. As we mentioned in the introduction, when relative clauses are associated with complex NPs of kinship relation like "o neto de ator" (the grandson of actor), it seems that the N2, although not introduced by an overt determiner, corresponds to the host that is preferred by the relative clause, at least in comparison with NPs of occupational relation, such as "o assistente de gerente" (the assistant of manager). By focusing on these two types of complex NPs (occupational relation and kinship relation), we intend to contribute to the 
understanding of the role of referentiality, understood in syntactic-semantic terms, in the processing of relative clauses, advancing the discussion started by Gilboy et al. (1995) in English and the critical approach offered by Bezerra (2017) based on BP data. We think the referentiality effect found by Gilboy et al. (1995) is not simply related to whether a noun is introduced or not by an overt determiner, but rather to the syntactic-semantic structure underlying the complex NPs in focus and to the syntactic-semantic complexity and the processing cost of the alternative analyses. We will talk more about this view in the General discussion, considering the results of the experiment that we will report in the next section.

\section{Experiment}

This experiment consisted of a questionnaire study and it aimed at investigating the influence of referentiality on relative clause interpretation in BP. More specifically, we want to test the Referentiality Principle, proposed by Gilboy et al. (1995), considering two types of complex NP to see whether the predicted effect of referentiality can be reduced to the presence of an overt determiner before a noun (making it referential) and to the discourse level representation developed for the sentences or, instead, as we tend to believe, whether such an effect needs to treated in terms of the syntactic-semantic structure underlying the complex NP the relative clause is associated with. To do so, we have manipulated two variables: N2 referentiality (in Gilboy et al's (1995) terms: referential N2 (overt determiner) and non-referential N2 (bare noun)) and Type of complex NP (occupational relation (type A) and kinship relation (type B)). These variables produced the following experimental conditions:

\section{a) Type A / Non-referential N2 (ANRN2)}

(7) O diretor demitiu o assistente de gerente que traiu a empresa na contabilidade. the director dismissed the assistant of manager that betrayed the company in the accounting

b) Type A / Referential N2 (ARN2)

(8) O diretor demitiu o assistente do gerente que traiu a empresa na contabilidade. the director dismissed the assistant of-the manager that betrayed the company in the accounting

\section{c) Type B / Non-referential N2 (BNRN2)}

(9) O enfermeiro acalmou o neto de ator que sofreu um acidente na rodovia.

the nurse calmed the grandson of actor that had an accident on the highway

\section{d) Type B / Referential N2 (BRN2)}

(10) O enfermeiro acalmou o neto do ator que sofreu um acidente na rodovia. the nurse calmed the grandson of-the actor that had an accident on the highway 
After each experimental sentence, participants had to answer a comprehension question focusing on the interpretation of the relative clause. For instance, considering the sentence in (a), they were presented to a question like "Quem traiu a empresa?" ("Who betrayed the company?") and two response options "( ) Assistente ( ) Gerente” (“( ) Assistant ( ) Manager”), which corresponded to N1 and N2 modification, in this order. Our dependent variable, therefore, was the response given by the participants to such questions: N1 or N2.

Our hypotheses and predictions were the following:

i. If Gilboy et al's (1995) predictions are on the right track, referentiality will influence relative clause interpretation and it will do it in the following way: there will be a preference for N1 interpretation when only the N1 is referential (i.e., when it is introduced by a determiner) (conditions (a) and (c)) (and there would be no reason to expect a difference between conditions (a) and (c)) but an attenuation of such a preference when the N2 is also referential (when it is also introduced by a determiner) (conditions (b) and (d)). In this rationale, we predict that conditions (a) and (c) will receive more N1 responses than conditions (b) and (d);

ii. If our intuitions are on the right track, along with Bezerra's (2017) proposal, referentiality will indeed influence relative clause interpretation but it will do so in a way that is dependent on the syntactic-semantic nature of the two types of complex NP we are focusing on: first, there will be a higher preference for N1 interpretation in condition (a) than in condition (b) because the alternative analysis (N2 modification) would be more complex in syntactic-semantic terms - in (a), differently from what we see in (b), the N2 refers to a concept (i.e., it is non-referential in Gilboy et al.'s (1995) sense) and modifying it with the relative clause would imply a change in its syntactic-semantic status towards a more specific reading, making the process of interpreting the sentence more demanding than just leaving it as a concept and associating the relative clause with the $\mathrm{N} 1$; second, the difference we have just predicted between conditions (a) and (b) will not be observed (at least not in the same proportion) in the comparison between conditions (c) and (d), because in (c) the N2, although not preceded by an overt determiner, does not seem to refer to a concept (as the N2 in (a) does), carrying, rather, a more specific reading with it. We could actually go even further and hypothesize that we will see the opposite pattern we have predicted for conditions (a) and (b) in the comparison (c) and (d) (i.e. a higher preference for $\mathrm{N} 2$ modification when the $\mathrm{N} 2$ is a bare noun than when it is introduced by an overt determiner) if we consider the fact that the N2 in (c), but not in (d), seems to require, semantically speaking, an additional restriction supportive of its more specific reading (intuitively, "O enfermeiro acalmou o neto de ator" ("the nurse calmed the grandson of actor") does not sound as good as "O enfermeiro acalmou o neto do ator" ("the nurse calmed 
the grandson of-the actor")); third, there will be a higher preference for N2 modification in (c) than in (a) for the reasons we have just outlined, which goes in the opposite direction of what might have been expected by Gilboy et al. (1995). Considering these thoughts and hypotheses, we predict a higher number of $\mathrm{N} 2$ responses in condition (b) than in condition (a), a higher number of $\mathrm{N} 2$ responses in condition (c) than in condition (a), and either no difference in the number of $\mathrm{N} 2$ responses in conditions (c) and (d) or a higher number of $\mathrm{N} 2$ responses in condition (c) than in condition (d).

\subsection{Method}

\subsubsection{Participants}

We followed two criteria in the process of recruiting participants for this study: they had to be native speakers of BP and be eighteen years or older. Ninetynine native speakers of BP participated voluntarily in this experiment. They had an average age of 33.16 years and varied with respect to their educational level: four had a high school degree, thirty-one were undergraduate students at universities in Brazil, thirty-one had a bachelor's degree, and thirty-three were taking or had completed a postgraduate course (either a lato sensu course or a stricto sensu course).

\subsubsection{Material}

The material consisted of two experimental lists, each one containing twentyfour experimental sentences (six sentences per experimental condition) and forty-eight fillers. The lists were constructed following a Latin Square distribution and a within-subjects design, which means that each subject was exposed to six instances of each experimental condition, but not to more than one version of an experimental item (subjects who read (a), for example, did not read (b)). The experimental sentences used in this experiment can be found in the Appendix.

The experimental sentences had the following structure: NP + VP + complex $\mathrm{NP}$ (N1 of N2) + Relative Clause (that + Verb(simple past) + Verb Complement + Adverb). The differences among our experimental conditions lied on how they encoded two linguistic factors: (i) the type of complex NP, with conditions (a) and (b) containing a complex NP of "occupational relation" and conditions (c) and (d) containing a complex NP of "kinship relation", and (ii) N2 referentiality, with conditions (a) and (c) containing an N2 that corresponds to a bare noun and conditions (b) and (d) containing an $\mathrm{N} 2$ that is introduced by a determiner. Our experimental sentences were ambiguous regarding the interpretation of the relative clause - it could be attached either to N1 or to N2. Moreover, as mentioned earlier, the comprehension question that appeared after each experimental sentence was followed by two options of response: one corresponding to N1 and the other corresponding to $\mathrm{N} 2$.

The task consisted of a questionnaire, which was elaborated using Google Forms. The experimental sentences and the fillers were presented to the 
participants in the following way: the sentence (be it experimental or filler) was presented on one screen and the corresponding comprehension question was presented on another screen. Right below the comprehension question, there were two options of response, which were displayed one on top of the other. In the experimental sentences, the first response option always corresponded to N1 and the second option always corresponded to N2. In the fillers, half of the correct responses corresponded to the option on the top and the other half corresponded to the option on the bottom. The two lists were pseudo-randomized, ensuring that the experimental sentences were always separated from one another by two fillers (one in which the correct response was the option on the top, and one in which the correct response was the option on the bottom).

\subsubsection{Procedures}

The questionnaire was elaborated using Google Forms, and the participants' responses were recorded and stored on Google Drive. By default, we shared the experiment's links with the participants by e-mail. In a few cases, though, we invited them in person. The first screen of the experiment corresponded to the informed consent, which was followed by a screen containing instructions on how to execute the task. We instructed participants to read sentences and answer questions about them: after reading a sentence, participants had to press "NEXT" to pass to the corresponding question, and, after answering this question based on how they had interpreted the sentence, they had to press "NEXT" again to go to the next sentence, and so on and so forth. We instructed participants to read the sentences at a natural pace, to answer the questions based on their first interpretation of the sentences (i.e., they should not go back to reread the sentence after reading the question), and not to go back and make changes in responses that had been already given. We estimated that the task must have been completed in an average of twenty minutes.

\subsection{Results}

We used the statistical software R to conduct the statistical analyses of our data. We conducted two types of analyses: chi-squared tests to see whether there was a difference between the number of $\mathrm{N} 1$ and $\mathrm{N} 2$ responses within each experimental condition, and binomial logistic regression models to predict the probability of obtaining an N1 response or an N2 response based on our predictor variables, that is, the variables we manipulated (N2 referentiality and type of complex NP).

Looking at the distribution of $\mathrm{N} 1$ and $\mathrm{N} 2$ responses within each experimental conditions, chi-squared tests revealed a significant difference in conditions ANRN2 and BNRN2, in which the N2 is non-referential and the N1 is referential $\mathrm{N} 1$, and no significant differences in conditions ARN2 and BRN2, in which both $\mathrm{N} 1$ and N2 are referential. The difference observed in conditions ANRN2 and BNRN2 was due to the fact that in both conditions the number of $\mathrm{N} 1$ responses 
was significantly higher than the number of N2 responses. The percentage of $\mathrm{N} 1$ and $\mathrm{N} 2$ responses per experimental condition and the results from the chisquared tests can be seen in Table 1:

Table 1. \% of N1 and N2 responses and $\mathrm{X}^{2}$ results per experimental condition.

\begin{tabular}{ccc} 
Experimental condition & \% N1 and N2 responses & \multicolumn{1}{c}{$X^{2}$ results } \\
ANRN2 & $\mathrm{N} 1: 66.84 \%$ & $\mathrm{X}^{2}(1, \mathrm{~N}=99)=67.34, \mathrm{p}<.001$ \\
& $\mathrm{~N} 2: 33.16 \%$ & \\
\hline ARN2 & $\mathrm{N} 1: 47.81 \%$ & $\mathrm{X}^{2}(1, \mathrm{~N}=99)=1.138, \mathrm{p}=0.28$ \\
& $\mathrm{~N} 2: 52.19 \%$ & \\
\hline & $\mathrm{N} 1: 57.24 \%$ & $\mathrm{X}^{2}(1, \mathrm{~N}=99)=12.451, \mathrm{p}<.001$ \\
\hline & $\mathrm{N} 2: 42.76 \%$ & \\
\hline & $\mathrm{N} 1: 50.34 \%$ & $\mathrm{X}^{2}(1, \mathrm{~N}=99)=0.026936, \mathrm{p}=0.86$ \\
\hline
\end{tabular}

Source: Created by the author.

Considering now the comparison between conditions, a binomial logistic regression analysis considering the two predictor variables ${ }^{4}$ revealed, first, a significant effect of $\mathrm{N} 2$ referentiality $(\beta=0.52885, \mathrm{SE}=0.08338, \mathrm{z}=6.343, \mathrm{p}<$ .001 ): a referential N2 significantly increased the probability of $\mathrm{N} 2$ responses in comparison with a non-referential N2. More specifically, a referential N2 in the NP of "occupational relation" (ARN2) significantly increased the probability of $\mathrm{N} 2$ responses in comparison with its non-referential counterpart (ANRN2) ( $\beta$ $=0.78833, \mathrm{SE}=0.11976, \mathrm{z}=6.583, \mathrm{p}<.001)^{5}$, and a referential $\mathrm{N} 2$ in the NP of "kinship relation" (BRN2) significantly increased the probability of N2 responses in comparison with its non-referential counterpart $(B N R N 2)(\beta=0.27814, \mathrm{SE}=$ $0.11667, \mathrm{z}=2.384, \mathrm{p}<0.01)^{6}$. Graph 1 illustrates these differences:

Graph 1: Distribution of N2 responses considering the effect of N2 Referentiality. Type A Type B

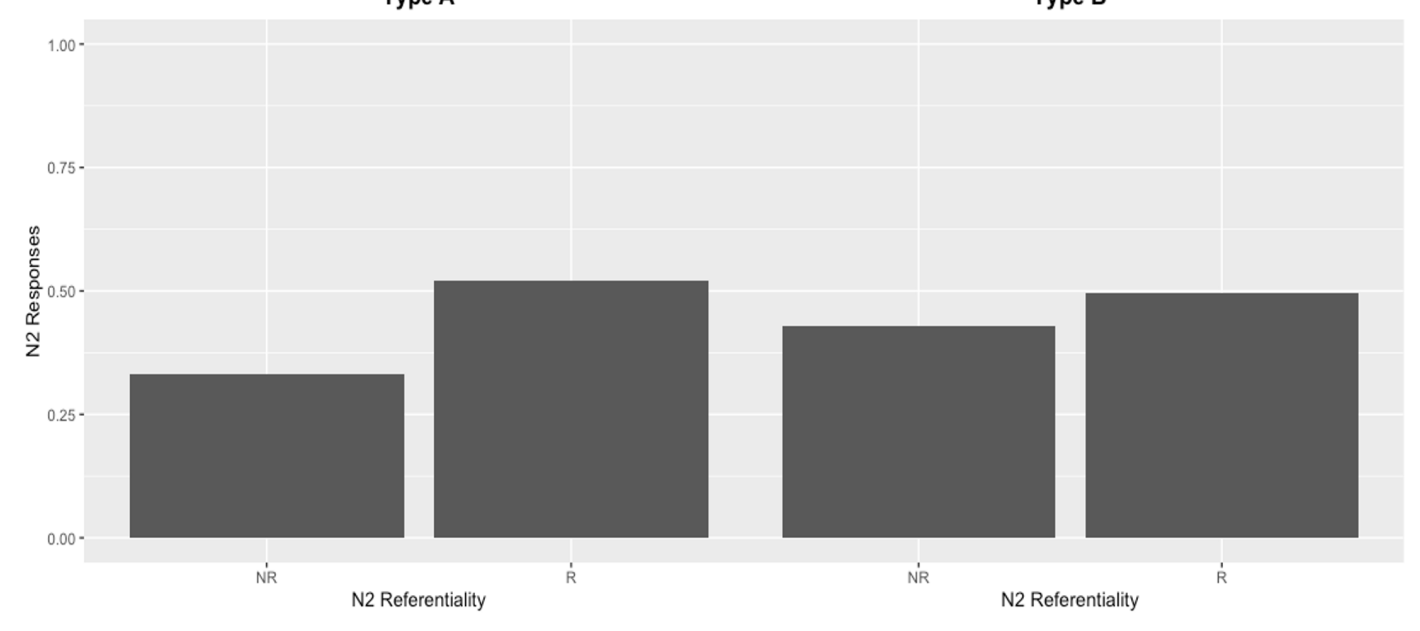


Second, the logistic regression analysis revealed a marginal effect of Type of Complex NP ( $\beta=0.14573, \mathrm{SE}=0.08334, \mathrm{z}=1.749, \mathrm{p}=0.08)$ : a complex NP of kinship relation (Type B) tended to increase the probability of N2 responses in comparison with a complex NP of occupational relation (Type A). More specifically, an NP of "kinship relation" with a non-referential N2 (BNRN2) significantly increased the probability of $\mathrm{N} 2$ responses in comparison with an NP of "occupational relation" with a non-referential N2 (ANRN2) $(\beta=0.40912, \mathrm{SE}=$ $0.12030, \mathrm{z}=3.401, \mathrm{p}<.001)^{7}$. This pattern was not found, however, in the case of a referential N2: there was no difference between an NP of "kinship relation" with a referential N2 (BRN2) and an NP of "occupational relation" with a referential $\mathrm{N} 2(\mathrm{ARN} 2)(\beta=-0.10107, \mathrm{SE}=0.11611, \mathrm{z}=-0.870, \mathrm{p}=0.38)^{8}$. Graph 2 illustrates these results:

Graph 2: Distribution of N2 responses considering the effect of the Type of Complex NP. NRN2 RN2

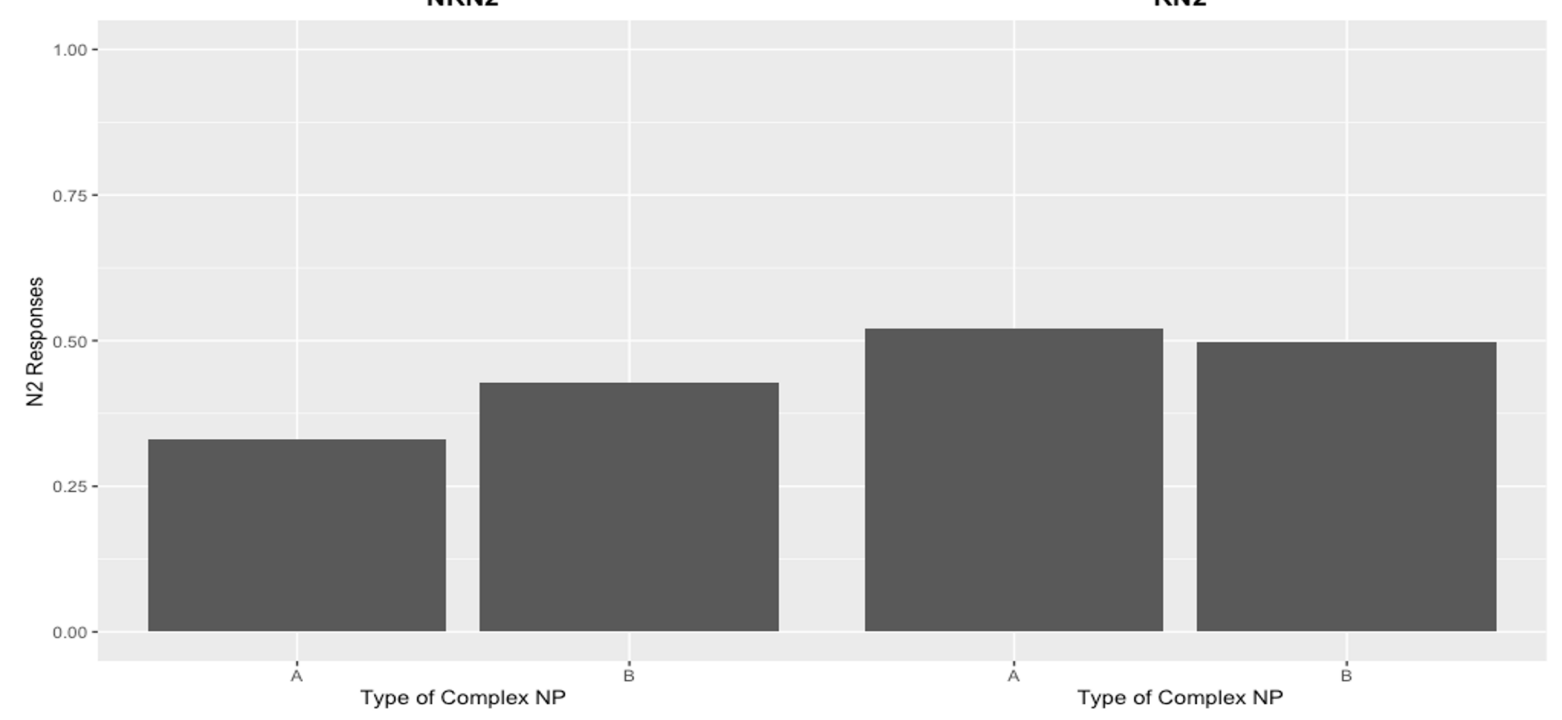

We also conducted a binomial logistic regression analysis considering an interaction between the two predictor variables. This analysis revealed two simple effects (the influence of one predictor for a specific level of the other predictor) and an interaction effect. The first simple effect revealed that a referential N2 increased the probability of N2 responses considering the A level ("occupational relation") of the predictor Type of Complex NP ( $\beta=0.78833$, SE $=0.11976, \mathrm{z}=6.583, \mathrm{p}<.001)$. The second simple effect showed that the complex $\mathrm{NP}$ of "kinship relation" (Type B) increased the probability of N2 responses considering the NRN2 level of the predictor N2 Referentiality $(\beta=0.40912, \mathrm{SE}=$ $0.12030, \mathrm{z}=3.401, \mathrm{p}<.001$ ), which can be seen in Graph 2. The interaction effect revealed that the referentiality effect (a referential N2 increasing the probability of $\mathrm{N} 2$ responses) was less steep for the conditions with a complex NP of "kinship reading" (Type $\mathrm{B})(\beta=-0.51019, \mathrm{SE}=0.16720, \mathrm{z}=-3.051, \mathrm{p}<.002)$, which can be seen in Graph 1.

These results are properly discussed in the next section. 


\subsection{Discussion}

We conducted this experiment to test two hypotheses: a discourse-oriented perspective (Gilboy et al., 1995) and a syntactic-semantic perspective (our own; Bezerra, 2017) on the influence of referentiality on relative clause interpretation. The general results are in line with the syntactic-semantic perspective we are standing up for in this paper.

The chi-squared results fully support Gilboy et al's (1995): in the conditions ANRN2 and BNRN2, in which the N2 is not introduced by an overt determiner, there was a preference for N1 modification; and in the conditions ARN2 and BRN2, in which both the $\mathrm{N} 1$ and the $\mathrm{N} 2$ are introduced by an overt determiner, there was not a significant difference in the number of $\mathrm{N} 1$ and $\mathrm{N} 2$ responses, showing that both nouns were available for the relative clause. These results are also in line with what we expected, except for the result of the condition BNRN2: in the condition ANRN2 the preference for N1 modification would be motivated by the fact that it corresponds to the simpler analysis available, since modifying the $\mathrm{N} 2$ would imply a revision of the syntactic-semantic analysis attributed to the $\mathrm{N} 2$ from a more generic reading towards a more specific one; in the conditions ARN2 and BRN2, we would predict that both nouns would be available in syntactic-semantic terms for the relative clause; finally, in the condition BNRN2, we were actually expecting a preference for $\mathrm{N} 2$ modification, since the $\mathrm{N} 2$ seems to carry a more specific reading, asking for a restrictive modification that would support it. This finding does not challenge our proposal, though, because of the more important and informative results we obtained in the other analyses.

The logistic regression analyses provided results that clearly support our syntactic-semantic view. While there was an effect of $\mathrm{N} 2$ referentiality showing that the preference for N1 attachment in the conditions ANRN2 and BNRN2 was attenuated in the conditions ARN2 and BRN2, we found, most importantly, that such an effect was less pronounced considering the conditions with a complex NP of "kinship relation" (Type B). This result is in line with our predictions, but do not seem to be in accordance with what is proposed by Gilboy et al. (1995), since it comes from the fact that the non-referential N2 in the condition with a complex NP of kinship relation motivated more an N2 modification than the non-referential N2 in the condition with a complex NP of occupational relation. Besides that, the effects we found regarding the type of complex NP also support our predictions, not seeming to be in line with what Gilboy et al. (1995) might have expected: there was a higher preference for N2 modification in the case of a complex NP of "kinship relation" (Type B) but only considering the condition with a non-referential $\mathrm{N} 2$, that is, the condition BNRN2 motivated more an N2 modification than the condition ANRN2 (no difference was not found comparing the conditions BRN2 and ARN2). This result supports our intuition that a non-referential N2 in a complex NP of "kinship relation" (Type B) is actually more referential than Gilboy et al. (1995) would have thought: the N2 in "o neto de ator" (the grandson of actor), 
although not introduced by an overt determiner, tends to be associated with a more specific reading than the $\mathrm{N} 2$ in "o assistente de gerente" (the assistant of manager), which is also not introduced by an overt determinant.

Taken together, the results obtained in this experiment seem to support our view and Bezerra’s (2017) view that referentiality effects are not simply related to whether a noun is introduced or not by an overt determiner, corresponding or not to an entity in the discourse model, as Gilboy et al. (1995) seem to propose in the Referentiality Principle. In fact, we think it is more reasonable to think of such effects in terms of the syntactic-semantic structure underlying the complex NPs in focus, as the crucial result concerning the difference between the nonreferential N2 interpretation in the two types of complex NPs we investigated strongly suggest. We will talk more about the syntactic-semantic structure underlying the complex NPs in focus and how it may affect relative clause interpretation in the next section.

\section{General Discussion}

Our aim in conducting the experimental research we reported in this paper was to investigate the influence of referentiality on relative clause interpretation. More specifically, we wanted to test the Referentiality Principle (Gilboy et al., 1995) in BP considering complex NPs of "occupational relation" and "kinship relation" to see whether an effect of referentiality would arise from the fact that relative clauses prefer hosts that are referential in the sense that they are introduced by an overt determiner and correspond to an entity in the discourse model, or whether such an effect would rather stem from the very syntacticsemantic nature of the complex NP the relative clause is associated with, which would bring into the discussion the difference between the alternative analyses in terms of processing cost. The results we presented in the previous section support our view, along the lines of what is hypothesized by Bezerra (2017), that the referentiality effects that gave rise to the Referentiality Principle could be associated with the syntactic-semantic structure of the complex NPs. Our experimental evidence says to us that we should take into account what the N1 and the N2 look like in syntactic-semantic terms when talking about the impact of referentiality on the interpretation of the type of structure we are focusing on and that we should do so before assuming, as Gilboy et al. (1995) seem to do, that what is relevant in this case is the discourse counterpart of the N1 and the N2, which, in turn, is shallowly related by them to the mere presence or absence of an overt determiner introducing such nouns.

We would like to discuss in more detail how our results support the syntacticsemantic hypothesis we are standing up for together with Bezerra (2017). First, we should bear in mind that Bezerra's (2017) hypothesis resulted from a consideration regarding a difference between the syntactic-semantic status of the $\mathrm{N} 1$ and the N2 in complex NPs in substance reading and how this difference could have an impact in terms of processing cost on relative clause interpretation 
- one analysis would be more complex and result in higher processing cost. The author hypothesized that a complex NP like "o sapato de couro" (the shoe of leather) works pretty much like a compound ${ }^{10}$ (Lieber \& Štekauer, 2009): the N1 and the $\mathrm{N} 2$ are linked together by the preposition and form a conceptual unit. The N2 corresponds to an NP and has the semantic type $<\mathrm{e}, \mathrm{t}\rangle$ and modifies the $\mathrm{N} 1$, initially an NP of semantic type $<\mathrm{e}, \mathrm{t}\rangle$ that gets saturated by the determiner " $o$ " (the), becoming a DP of semantic type e. The N1 and the N2, in this rationale, would not be equally available for the relative clause at the syntactic-semantic level. What about the syntactic-semantic status of the N1 and the N2 in the complex NPs we have been focusing on in this paper, namely, the complex NP of occupational relation and the complex NP of kinship relation?

The complex NP of occupational relation seems to behave like the complex NP of substance reading in the sense that it reminds us of a compound ${ }^{11}$. If this observation is on the right track, the $\mathrm{N} 1$ and the $\mathrm{N} 2$ would have the same syntactic-structure status as the nouns in the complex NP of substance reading: " $d e$ " (of) would not be a thematic preposition, but just a linking element putting together the N1, an NP of type $<e, t>$, and the N2, and NP of type $<e, t>$. In the resulting complex NP, the N1 would correspond to a DP after being saturated by the determiner " $o$ " while the N2 would probably remain as an NP $(<e, t>)$. In this case, the preference for N1 modification we found in the condition ANRN2 ("o assistente de gerente que..." (the assistant of manager)) would result from the fact that it would be the simpler option: attaching the relative clause to the N2 would imply changing the syntactic-semantic structure already attributed to the complex NP and probably adding more structure (such as a DP node related to the more specific reading of the N2 that would arise from the restrictive modification), which would be in accordance with Bezerra's (2017) hypothesis and predictions. Assuming that both the complex NP of substance reading and the complex NP of occupational relation work as compounds, our account and Bezerra's (2017) account could be summarized in the idea that N1 modification is preferred in these cases because the alternative analysis would require "breaking" the compound in order to access the $\mathrm{N} 2$ more independently ${ }^{12}$, which would be related to a higher processing cost, for the reasons we have already outlined previously in this paragraph.

Would the previous analysis be a precise picture of what happens in complex NPs of kinship relation? Our answer is no, and the reason is that, in this case, we would not have a compound: the $\mathrm{N} 2$ would actually be an argument of the $\mathrm{N} 1$, with the preposition acting as a case marker ${ }^{13}$. This type of complex NP is particularly interesting because the N2 corresponds to a bare singular in an argument position, which is a linguistic situation that has been the target of extensive debate among researchers from the areas of Formal Semantics and Syntax (Stowell, 1991; Longobardi, 1994; Chierchia, 1998, 2010; Coene \& D’hulst, 2003). Roughly speaking, the discussion is about whether an NP $(<e, t>)$ can work by itself as an argument or whether we would necessarily need a DP (type e), either with an overt $\mathrm{D}$ or with a null $\mathrm{D}$, in an argument position. $\mathrm{BP}$ is a language 
in which we see bare singulars occupying argument positions (different from what we find in English), but the syntactic-semantic status of such nominal expressions has been a source of controversy in the literature. We can mention at least three approaches to bare singulars in BP. Schmitt and Munn (1999), for example, argue that they are number neutral (correspond to DPs without Number projection) and denote names of kinds, assuming a difference between bare singulars and mass nouns. Müller (2002), on the other hand, proposes that bare singulars in BP are indefinites à la Heim (1982), that is, they are predicates $(\mathrm{NPs},<\mathrm{e}, \mathrm{t}>$ ) that introduce a variable in the logical form of the sentences they belong to, and are number neutral. Finally, Pires de Oliveira and Rothstein (2011) propose that bare singulars in BP are pretty much like mass nouns (more precisely, like "fake" mass nouns, such as "furniture") and that both of them denote kinds. Bare singulars would correspond to DPs (type e). This approach was recently revised by Pires de Oliveira and Beviláqua (2020) in the following sense: bare singulars indeed denote kinds (they correspond to DPs (type e)), but they are actually underspecified for atomicity - they are neither mass nor count nouns. In our discussion we are going to assume Pires de Oliveira and Beviláqua’s (2020) approach.

In our complex NP of kinship relation, both the N1 and the N2 would correspond to DPs (type e), but the bare singular would denote kinds by default, being related to a more generic reading. Our sentences, however, correspond to episodic contexts (see the perfective aspect of the verbs, e.g.), and this may be the cause of the weirdness we feel in a sentence like (11):

\section{(11) O enfermeiro acalmou o neto de ator.}

the nurse calmed the grandson of actor

since, in this case, an episodic environment would be motivating a more specific reading of a noun that would refer, otherwise (or at first), to a concept $t^{14}$. Our intuition regarding a preference for $\mathrm{N} 2$ modification in this case would be related to the fact that the relative clause would help to specify or identify the N2. The fact that we found a preference for N1 modification in the condition BNRN2 supports the idea that the $\mathrm{N} 2$ corresponds to a DP (type e) and denotes the kind; but, at the same time, the fact that we found a difference between BNRN2 and ANRN2 shows that the episodic context is encouraging a more specific reading of the N2. This view that the bare singular in our complex NP of kinship relation corresponds to a DP (type e) and can have a more specific reading highlights the imprecision of Gilboy et al's (1995) assumption that a referential noun would be introduced by a determiner (they mean "by an overt determiner") and a nonreferential would not be introduced by a determiner: we can have a noun that is not introduced by an overt determiner but still carries a more referential reading.

Having discussed in more detail the syntactic-semantic approach we are following in this paper, we would like to point out some aspects of Gilboy et al.'s (1995) proposal that, in our view, should have been more carefully addressed 
by the authors in their initiative of proposing an interpretive principle. The first aspect refers to one that we have been talking about throughout the paper, namely, the view that relative clauses preferentially seek for hosts that are referential (corresponding to a discourse entity) when they are introduced by a determiner (meaning: an overt determiner). As we have just seen, a bare noun (or bare singular) in a complex NP of kinship relation may be more preferred by the relative clause than a bare noun in a complex NP of occupation relation, and both of them are not introduced by an overt determiner. The difference here lies in the relationship between the N1 and the N2 and how this affects their syntactic-semantic status: the N2 in occupational relation NPs are NPs (type $<e, t>$ ), whereas the N2 in kinship relation NPs are DPs (type e). Considering these different underlying structures, N1 modification and N2 modification would imply different structures and different processing costs, as we have already suggested. For the time being, we will not dare to establish a specific idea of what means to be a referential noun in syntactic, semantic, and discourse representation terms, but what our considerations about the structure underlying the complex NPs in focus seem to suggest is that a referential noun would be related to a DP (type e) structure, which in turn may be more or less referential depending on whether it refers to a concept or to a more specific entity, and a non-referential noun would be related to an NP (type $<e, t>$ ) structure. In this regard, we think our research was particularly informative and relevant because it gave the possibility of testing the Referentiality Principle in structures that would not be grammatically available in English: the English counterpart of (11), for example, would not be naturally available because this language does not seem to allow for a bare singular in an argument position (Chierchia, 2010).

The second aspect we would like to highlight is that, if the way we are treating the complex NPs in focus is on the right track, the N1 and the N2 would not be equally available for the relative clause not only at the discourse level - they actually do not seem to have the same syntactic-semantic starting point (even so in the case of the bare singular in the complex NP of kinship relation: both the $\mathrm{N} 1$ and the N2 would correspond to DPs, but there is still a difference between them either because the $\mathrm{N} 2$ would refer to a concept by default or because our episodic context would actually favor the $\mathrm{N} 2$ modification). We think this is a crucial thing to consider when postulating a principle: if we attribute a difference to the discourse level and make predictions based on that, as Gilboy et al. (1995) did, we seem to be assuming that all the other things are equal (other things here = syntactic-semantic status), which do not seem to be the case. If we assume, as we indeed tend to do, that the process of interpretation more often than not presupposes a syntactic structure (Frazier, 1979; Frazier \& Rayner, 1982; Frazier \& Clifton, 1996; Frazier, 1999) and that a discourse representation would, in turn, presuppose a syntactic-semantic structure, we cannot just formulate a principle and make predictions in terms of differences in the discourse representation when there might be relevant differences at lower levels that could account for the facts or preferences in hand. The parser will process the syntactic structure 
underlying the complex NPs and a semantic processor might also be working simultaneously attributing a semantic representation to the syntactic structure developed by the parser, all this prior to the ultimate development of a discourse representation. What we are suggesting is that those syntactic and semantic processes may be responsible for the referentiality effects we, Bezerra (2017), and Maia and Finger (2007) have found in BP and the referentiality effects Gilboy et al. (1995) have found in English, mainly considering the conditions in which the $\mathrm{N} 1$ is introduced by an overt determiner and the $\mathrm{N} 2$ is a bare noun.

The third aspect we want to emphasize is that Gilboy et al. (1995) proposed the Referentiality Principle based on sentences that have a clear tendency to N1 attachment. What they did was to get sentences with substance NPs and quantity NPs, in which a referential N2 (i.e., an N2 introduced by a determiner, in Gilboy et al.'s (1995) view) is not easily accepted ${ }^{15}$, show the obvious preference for N1 attachment in these cases (obvious because the relative clause would be able to see first only the $\mathrm{N} 1$, that is, the $\mathrm{N} 2$ host would have to be somehow created by changing the syntactic-semantic structure of the complex NP), and propose a generalization that sounds more like a description of what we find in a biased situation than an explanation for a specific preference of analysis given the syntactic-semantic structures implied by the alternatives analyses at stake. We are suggesting that the Referentiality Principle lacks in explanatory power and that the situations it tries to capture could be better dealt with in terms of generalizations regarding preferences for less complex analyses (Frazier, 1979), for analyses that are first available for the parser (Frazier, 1987), and for the analyses that are consistent with the syntactic-semantic structure that has already been attributed to the input up to the choice point at issue. This last observation is captured by the Minimal Revisions Principle, postulated by Frazier and Clifton (1998, p. 155): “Don't make an unnecessary revision. When revision is necessary, make the minimal revision consistent with the error signal, maintaining as much of the already assigned structure and interpretation as possible". If what we are saying is indeed the case, the Referentiality Principle would no longer exist as such.

In response to our criticisms, Gilboy et al. (1995) could make the following objections. First, they could say that it is not true that they ignored altogether the syntactic-semantic structure of the complex NPs, because they had to talk about the noun that would establish the current processing thematic domain: was the $\mathrm{N} 2$ an argument of the N1? Was the N2 an argument of the preposition? Indeed, they did show explicitly how we could treat the N1 and the N2 in these terms, and they did so in order to test and give support to the Construal Hypothesis (Frazier \& Clifton, 1996), but they developed more this discussion with respect to what they called "of genitives", that is, complex NPs in which both the N1 and the $\mathrm{N} 2$ would be introduced by a determiner, and, therefore, be referential - the Referentiality Principle would not be of much help in this case. The complex NPs they used to formulate such a principle, namely, complex NPs of substance reading and complex NPs of quantity reading did not receive the proper attention in this regard. Second, they could argue that they were not inflexible in the 
assumption that a noun would be necessarily non-referential if not introduced by an overt determiner, in fact assuming the softer idea that a noun that is not introduced by a determiner may not be referential in the intended sense. This position can be explicitly seen in the following passage: "if two NPs exist within the thematic processing domain with which an RC is associated, and if one of them is without a determiner in a way that makes it non-referential, that NP will be a less preferred host for an RC." (Gilboy et al., 995, p. 136), where RC stands for relative clause. We acknowledge that, but this only shows how slippery the referential status of a noun can be and, for us, how the authors were rushed in their attempt to catch a pattern and propose a principle, which, in our view, only opens the door to "post hoc" analyses or discussions in order to account for cases that did not match the premature predictions.

We should now think of our syntactic-semantic hypothesis in light of the sentence processing models we have in the literature. As we have seen earlier in this paper, the Referentiality Principle was proposed within the framework of the Construal Hypothesis (Frazier \& Clifton, 1996, 1997), which can be treated as a hybrid processing model in the sense that it assumes that primary phrases are analyzed according to the predictions of the Garden-Path Theory (the parser is encapsulated and develops syntactic representations based only on syntactic information, independently of the type of phrase it encounters) and secondary phrases are analyzed through association, which involves an initial syntactic underspecification followed by a process of interpretation that determines the syntactic analysis based on syntactic and non-syntactic information. That is, in the processing of secondary phrases, non-syntactic information could determine the syntactic analysis. The Referentiality Principle, therefore, is understood as a non-syntactic principle that operates in the interpretation of relative clauses, determining an initially underspecified structure. In this case, according to Gilboy et al. (1995), information related to the discourse model would determine the syntactic analysis. The very formulation of the Construal Hypothesis can be seen as the acknowledgment that non-syntactic information may play a determinant role in syntactic parsing. Such a role, however, is still restricted since limited to the processing of secondary phrases. The question that arises here is whether our proposal that the referentiality effect has a syntactic-semantic nature would challenge the Construal's assumption that the processing of secondary phrases is to some extent not modular (in the sense that the syntactic analysis may be determined by non-structural information coming from semantics, discourse or pragmatics, for example). Our answer is no. By proposing a syntactic-semantic treatment for the referentiality effect our aim is not to attack the idea that information present in the discourse model can influence syntactic processing, but rather that the phenomenon at issue has a syntactic-semantic nature and should be treated as such: the alternative analyses ( $\mathrm{N} 1$ and N2 modification) should be discussed in terms of the syntactic-semantic representations of the complex NPs to which the relative clauses are associated, and not in terms of the discourse models developed for the sentences. The core issue is that the alternative analyses 
differ from each other at the syntactic-semantic level. While we are not putting into question the somewhat interactive behavior of the parser in the case of secondary phrases, we are assuming that processing a sentence involves extracting its syntactic skeleton and developing the corresponding semantic representation, with the discourse models being generated based on those syntactic-semantic processes. In this case, thinking in terms of the Construal Hypothesis, we are entertaining the idea that, after associating the relative clause into the current thematic processing domain, the most relevant information for determining one analysis would be the syntactic-semantic one and that such information would be available for the parser before the discursive one. By taking the Construal's position, we are departing from what is proposed by fully interactive processing models, the so-called constraint-satisfaction models (MacDonald, Pearlmutter \& Seidenberg, 1994; Trueswell, Tanenhaus \& Kello, 1993, among others), since they assume that the parser can always make immediate use of all potentially relevant sources of information and they tend to be lexicalist (Pickering \& van Gompel, 2006), assuming that syntactic structures emerge from the activation of syntactic projections stored in the lexical entry of words. In general, such models assume that all syntactic analyses of an ambiguous structure are activated in parallel, and their activation is determined by various constraints, such as frequency and probabilistic contextual constraints. Putting aside the specificities of each sentence processing model, the fact is that we have to account for the influence of various sources of information on syntactic processing. One of the issues we have to deal with and focus on is the architecture the language processor would have to have in order to access, use and coordinate different types of information in real-time processing. The Construal Hypothesis, for example, did not propose a proper mechanism that would carry out the interpretation process they argued for. Although our experiment does not allow us to address this issue in more detail (we did not look at real-time processing), it was a step in that direction. We can say that the syntactic-semantic structure of complex NPs plays a role in relative clause interpretation, with additional studies being necessary to investigate how such an influence would emerge in the time-course of sentence comprehension.

We conclude by saying that we hope to have given in this paper a more detailed account of how referentiality, understood in syntactic-semantic terms, may affect relative clause interpretation. The two types of complex NPs we investigated enabled us, on the one hand, to make a productive discussion about the limitations we see in the Referentiality Principle (Gilboy et al., 1995) and, on the other hand, to advance Bezerra's (2017) proposal regarding a more syntactic-semantic view of the referentiality effects we have discussed in this paper. Relative clause processing is undoubtedly a thought-provoking phenomenon. It is interesting to see how superficially similar sentences can in fact have different underlying syntacticsemantic structures, as we saw in the case of our complex NPs, for example, and it is even more fascinating to see how such invisible structures can impact the way we interpret sentences. In this sense, among the many questions that remain open after this general discussion, we would like to emphasize one (or two closely 
related): considering our sentences with kinship relations NPs containing a bare singular, will the N2 be immediately analyzed as a kind denoting expression by default in real-time processing, along the lines of what Pires de Oliveira and Rothstein (2011) and Pires de Oliveira and Beviláqua (2020) propose in more theoretical terms? If so, will the change we predicted from a more generic to a more specific reading in an episodic context be so fast as to immediately influence the processing and interpretation of the upcoming relative clause? These questions are very important (as a matter of fact, we are working on them in our current research) because they are basically asking us to conduct more specific research on semantic processing, which is the way to go if we want to understand in more detail the intriguing phenomenon of sentence interpretation.

\section{Acknowledgments}

The research reported here was part of the postdoctoral project we developed at the University of Toronto from 2018 to 2019. We would like to thank the CAPES Foundation (Brazilian Federal Agency for Support and Evaluation of Graduate Education) for the scholarship awarded to us to conduct our postdoctoral research at the University of Toronto (process 88881.171537/2018-01). We also would like to thank the two anonymous reviewers for their comments and suggestions.

\section{Notes}

1. Gilboy et al. (1995) also investigated whether definiteness would have an influence on the interpretation of relative clauses. They had a condition with a definite N1 ("the sweater", "el jersey") and a condition with an indefinite N1 ("a sweater", "un jersey"). Considering that a relative clause would be preferentially used to specify a particular definite referent of a noun phrase, the authors entertained the (exploratory) hypothesis that a definite $\mathrm{N} 1$ would attract more the relative clause than an indefinite N1. The results, however, did not support this hypothesis: the authors did not find a significant effect of definiteness on relative clause interpretation in their experiment.

2. When the author says that the N1 corresponds to a DP, she is considering that the modification relation has already been established: the preposition " $d e$ " (of) connects the NP (<e,t $>$ ) "couro" (leather) with the NP (<e,t>) "sapato" (shoe), and then the resultant NP (<e,t>) "sapato de couro" (shoe of leather) is saturated by the determiner " $o$ " (the). This is coherent with the idea seen in the relative clause processing literature that $\mathrm{N} 1$ attachment can be thought of as an attachment to the complex NP itself, that is, the complex NP as whole.

3. We could say they are equally available in linguistic terms if we assume the relative clause is attached to an NP (it would modify the N1 before the determiner comes into place, e.g.), but we are also considering what happens in terms of processing when $\mathrm{N} 1$ or N2 attachment is chosen, as will become clear soon.

4. Model: $\operatorname{glm}($ formula $=$ Response $\sim$ Referentiality + Type, family $=$ binomial(link = "logit"), data $=$ datai).

5. Model: $\operatorname{glm}($ formula $=$ Response $\sim$ Referentiality, family $=$ binomial(link $=$ "logit"), data = dataa).

6. Model: $\operatorname{glm}($ formula $=$ Response $\sim$ Referentiality, family $=$ binomial(link $=$ "logit"), data = datab). 
7. Model: $\operatorname{glm}($ formula $=$ Response $\sim$ Type, family $=$ binomial $($ link $=$ "logit"), data $=$ dataab4).

8. Model: $\operatorname{glm}($ formula $=$ Response $\sim$ Type, family $=$ binomial $($ link $=$ "logit"), data = dataab5).

9. Model: $\operatorname{glm}\left(\right.$ formula $=$ Response $\sim$ Referentiality ${ }^{*}$ Type, family $=$ binomial(link $=$ "logit"), data $=$ datai).

10. We would like to thank professor María Cristina Cuervo (University of Toronto) for having pointed out to us this analysis of the complex NP of substance reading as a compound.

11. We would like to thank professor Ana Teresa Pérez-Leroux (University of Toronto) for her observation that the complex NP of occupational relation could be seen as a compound.

12. This seems to be a productive idea in the sense that we could test other types of complex NPs to see whether the same predictions could be applied. For example, the NP "o vestido de noiva" (the dress of bride) seems to work as a compound, differently from what we see in an NP like "o vestido de atriz". If these intuitions are on the right track, we could expect that a relative clause associated to an NP like "o vestido de noiva" would prefer the $\mathrm{N} 1$ as its host, whereas there would be a preference for N2 in NPs like "o vestido de atriz". In this regard, we are aware of the fact that we need to provide a more solid theoretical support for the idea that complex NPs of substance reading and the complex NPs of occupational relation indeed work as compounds. We are working on that in our current research. Besides that, as pointed out to us by one of the reviewers, it could be informative to look at relative clauses associated with NPs of inalienable possession such as "A enfermeira limpou o dedo da/de mão que machucou no acidente" (the nurse cleaned the finger of (the) hand that was injured in the accident). Intuitively, the use of this type of NP with the N2 without a determiner sounds unnatural and might motivate an $\mathrm{N} 2$ modification in order to provide a referential status to the N2. It would not present what we are calling a compound reading, therefore.

13. This is the position assumed by Gilboy et al. (1995) to support their view that both nouns would be available within the current processing thematic domain.

14. In this regard, the comparison with a sentence like "Enfermeiro acalma neto de ator" (nurse calms grandson of actor) may be informative. We would like to thank professor Roberta Pires de Oliveira for having suggested this analysis to us.

15. Our present work contributes also in this regard because we used complex NPs in which a referential N2 (in Gilboy et al's (1995) sense) would be naturally accepted.

\section{References}

Altmann, G. T. M. \& Steedman, M. (1988). Interaction with context during human sentence processing. Cognition, 30, 191-238.

Bezerra, G. B. (2017). A influência da referencialidade no processamento de orações relativas associadas a NPs complexos do tipo "substância" (Doctoral thesis, Federal University of Paraíba, João Pessoa, Brasil).

Bezerra, G. B. (2019). The Influence of Referentiality, Definiteness, and "P+D" Contraction on Relative Clause Interpretation. DIACRÍTICA, 33 (2), 116-140.

Bezerra, G. B. \& Leitão, M. M. (2017). The construal hypothesis and relative clause processing: The effect of the referentiality principle in Brazilian Portuguese. In L. Escobar, V. Torrens \& T. Parodi (Eds.), Language processing and disorders (pp. 54-74). Newcastle upon Tyne: Cambridge Scholars Publishing. 
Bezerra, G. B., Leitão, M. \& Medeiros, L. (2017). A influência da referencialidade no processamento de orações relativas em português brasileiro. Revista de Estudos da Linguagem, 25 (3), 1397-1431.

Chierchia, G. (1998). Reference to kinds across languages. Natural Language Semantics, 6, 339-405.

Chierchia, G. (2010). Mass nouns, vagueness and semantic variation. Synthèse, 174, 99-149.

Coene, M. \& D'hulst, Y. (2003). Introduction: The syntax and semantics of noun phrases, Theoretical background. In M. Coene \& Y. D'hulst (Eds.), From NP to $D P$ - Volume 1: The syntax and semantics of noun phrases (pp. 1-46). Amsterdam / Philadelphia: John Benjamins Publishing Company.

Cuetos, F. \& Mitchell, D. C. (1988). Cross-linguistic differences in parsing: Restrictions on the use of the Late Closure strategy in Spanish. Cognition, 30, 73-105.

Fodor, J. D. (1998). Learning to parse? Journal of Psycholinguistic Research, 27(2), 285-319.

Fodor, J. D. (2002). Psycholinguistics cannot escape prosody. In: Speech Prosody Conference, 2002, Aix-en-Provence, France. Proceedings of the Speech Prosody, Aix-en-Provence: Laboratoire Parole et Langage, 83-88.

Frazier, L. (1979). On comprehending sentences: Syntactic parsing strategies. Unpublished doctoral dissertation, University of Connecticut.

Frazier, L. (1987). Sentence Processing: A Tutorial Review. In Coltheart, M. (Ed.). Attention and Performance XII: The Psychology of Reading (pp. 559-586). Mahwah, NJ: Erlbaum.

Frazier, L. (1990). Exploring the architecture of the language-processing system. In G. Altmann (Ed.), Cognitive Models of Speech Processing: Psycholinguistic and Computational Perspectives (pp. 409-433). Cambridge, MA: MIT Press.

Frazier, L. (1999). On sentence interpretation. Dordrecht: Kluwer Academic Publishers.

Frazier, L. \& Fodor, J. D. (1978). The sausage machine: a new two-stage parsing model. Cognition, 6, 291-325.

Frazier, L. \& Clifton, C. Jr. (1996). Construal. Cambridge, MA: MIT Press Cambridge.

Frazier, L. \& Clifton, C. Jr. (1997). Construal: overview, motivation, and some new evidence. Journal of Psycholinguistic Research, 26(3), 277-295.

Frazier, L. \& Clifton, C. Jr. (1998). Sentence reanalysis, and visibility. In J. D. Fodor \& F. Ferreira (Eds.), Reanalysis in Sentence Processing (pp. 143-176). Dordrecht: Kluwer Academic Publishers.

Frazier, L. \& Rayner, K. (1982). Making and Correcting Errors during Sentence Comprehension: Eye Movements in the Analysis of Structurally Ambiguous Sentences. Cognitive Psychology, 14, 178-210.

Gilboy, E., Sopena, J., Clifton, C. Jr. \& Frazier, L. (1995). Argument structure and association preferences in Spanish and English complex NPs. Cognition, 54, 131167.

Gibson, E., Pearlmutter, N., Canseco-Gonzalez, E. \& Hickok, G. (1996). Recency preference in the human sentence processing mechanism. Cognition, 59, 23-59.

Grillo, N. \& Costa, J. (2014). A novel argument for the universality of parsing principles. Cognition, 133, 156-187.

Heim, I. (1982). The semantics of definite and indefinite noun phrases. Amherst, MA: University of Massachusetts doctoral dissertation. 
Hemforth, B., Konieczny, L., Seelig, H. \& Walter, M. (2000). Case matching and relative clause attachment. Journal of Psycholinguistic Research, 29, 81-88.

Hemforth, B.; Fernandez, S.; Clifton, C.; Frazier, L.; Konieczny, L. \& Walter, M. (2015). Relative clause attachment in German, English, Spanish and French: effects of position and length. Lingua, 166, 43-64.

Higginbotham, J. (1985). On semantics. Linguistic Inquiry, 16, 547-594.

Karimi, H. \& Ferreira, F. (2016). Good-enough linguistic representations and online cognitive equilibrium in language processing. The Quarterly Journal of Experimental Psychology, 69(5), 1013-1040.

Lieber, R. \& Štekauer, P. (2009). The Oxford Handbook of Compounding. New York: Oxford University Press.

Longobardi, G. (1994). Reference and proper names: a theory of N- movement in syntax and logical form. Linguistic Inquiry, 25, 609-665.

Macdonald, M. C.; Pearlmutter, N. J. \& Seidenberg, M. S. (1994). The Lexical nature of syntactic ambiguity resolution. Psychological Review, 101, 676-703.

Maia, M. \& Finger, I. (2007). Referencialidade e domínio temático na compreensão de orações relativas curtas e longas em português. Linguística, 3(2), 249-278.

Maia, M., Fernández, E. M., Costa, A. \& Lourenço-Gomes, M. C. (2006). Early and late preferences in relative clause attachment in Portuguese and Spanish. Journal of Portuguese Linguistics, 6, 227-250.

Mitchell, D. C. \& Cuetos, F. (1991). The origins of parsing strategies. In C. Smith (Ed.), Current issues in natural language processing (pp. 1-12). Austin: University of Texas, Centre for Cognitive Science.

Miyamoto, E. T. Relative clause processing in Brazilian Portuguese and Japanese. (1999). Tese de Doutorado. Massachusetts Institute of Technology - MIT. Cambridge, MA.

Miyamoto, E. (2005). Orações relativas ambíguas e a homogeneidade do processamento de sentenças. In M. Maia \& I. Finger (Eds.), Processamento da Linguagem (pp. 71-90). Pelotas: Educat.

Müller, A. L. (2002). The semantics of generic quantification in Brazilian Portuguese. PROBUS, 14(2), 279-298.

Pickering, M. J. \& van Gompel, R. P. G. (2006). Syntactic Parsing. In J. Traxler \& M. A. Gernsbacher (Eds.), Handbook of Psycholinguistics (pp. 455-503). Amsterdam, The Netherlands: Elsevier.

Pires de Oliveira, R. \& Rothstein, S. (2011). Bare singular noun phrases are mass in Brazilian Portuguese. Língua, 121, 2153-2175.

Pires de Oliveira, R. \& Beviláqua, K. (2020). Brazilian bare nouns in quantity judgments: kinds and atomicity. In R. Pires de Oliveira; I. Emmel \& S. Quarezemin (Eds.), Brazilian Portuguese, Syntax and Semantics: 20 years of NEG (pp. 192211). Amsterdam: John Benjamins.

Ribeiro. A. J. (1998). Um caso de não aplicação de Late Closure no português do Brasil. Rio de Janeiro: UFRJ/FL, Mimeo.

Ribeiro. A. J. (2004). Late Closure em parsing no português do Brasil. Tese de Doutorado. Universidade Federal do Rio de Janeiro, Rio de janeiro, Brasil.

Ribeiro. A. J. (2005). Late Closure em parsing no português do Brasil. In M. Maia \& I. Finger (Eds.) Processamento da Linguagem (pp. 51-70). Pelotas: EDUCAT.

Schmitt, C. \& Munn, A. (1999). Against the nominal mapping parameter: bare nouns in Brazilian Portuguese. In Proceedings of NELS 29. pp. 339-353. 
Stowell, T. (1991). Determiners in NP and DP. In K. Leffeland \& D. Bouchard (Eds.), Views on phrase structure. (pp. 37-56). Dordrecht: Kluwer.

Trueswell, J. C.; Tanenhaus, M. K.; Kello, C. (1993). Verb-Specific Constraints in Sentence Processing: Separating Effects of Lexical Preference from Garden-Paths. Journal of Experimental Psychology, 19, 528-553.

Recebido em: 30/06/2021 Aceito em: 24/11/2021

Appendix. Sentences used in our experiment. The four conditions are presented in the following way: (I) Type A: of (ANRN2) /of-the (ARN2); (II) Type B: of (BNRN2) /of-the (BRN2).

\section{(I) Type A}

1. O arquiteto instruiu o ajudante de pedreiro/do pedreiro que fez uma sugestão no encontro.

2. O diretor demitiu o assistente de gerente/do gerente que traiu a empresa na contabilidade.

3. O técnico parabenizou o massagista de jogador/do jogador que mostrou competência no torneio.

4. O guarda alertou o motorista de cantor/do cantor que xingou o trânsito na estrada.

5. O adolescente destratou o aprendiz de eletricista/do eletricista que começou o trabalho no prédio.

6. O coordenador orientou o tutor de aluno/do aluno que apresentou dificuldade na escola.

7. $\mathrm{O}$ apresentador indagou o advogado de prefeito/do prefeito que relatou a corrupção na entrevista.

8. A imprensa sondou o assessor de vereador/do vereador que acobertou o roubo na eleição.

9. A coordenadora admirou o cuidador de idoso/do idoso que chegou ao asilo no Natal.

10. O maestro contatou o professor de violinista/do violinista que deu uma entrevista na rádio.

11. O delegado questionou o chefe de policial/do policial que desobedeceu uma ordem na missão.

12. O jornalista elogiou o auxiliar de repórter/do repórter que fez uma matéria no presídio.

\section{(II) Type B}

1. O deputado ouviu o avô de comerciante/do comerciante que perdeu a casa no desastre.

2. O juiz interrogou o afilhado de fazendeiro/do fazendeiro que comercializou droga no evento. 
3. O enfermeiro acalmou o neto de ator/do ator que sofreu um acidente na rodovia.

4. O porteiro reconheceu o tio de guitarrista/do guitarrista que deixou uma encomenda na portaria.

5. O colecionador encontrou o primo de pintor/do pintor que ofertou o quadro na televisão.

6. O programa entrevistou o pai de dançarino/do dançarino que discutiu o preconceito no teatro.

7. O organizador apresentou o sobrinho de pianista/do pianista que produziu um disco no festival.

8. O segurança aconselhou o irmão de governador/do governador que começou uma discussão no fórum.

9. A secretária auxiliou o filho de presidente/do presidente que recebeu uma intimação na reunião.

10. A população identificou o bisneto de escritor/do escritor que divulgou a obra na cidade.

11. O protagonista visitou o cunhado de produtor/do produtor que criticou a novela no jornal.

12. O grupo conheceu o padrinho de surfista/do surfista que organizou a festa na praia. 